Management of hypertension: summary of NICE guidance. BMJ 2011; 343: d4891.

3. Lovibond $K$, Jowett $S$, Barton $P$, et al. Costeffectiveness of options for the diagnosis of high blood pressure in primary care: a modelling study. Lancet 2011; 378(9798): 1219-1230.

4. McManus RJ, Mant J, Bray EP, et al. Telemonitoring and self-management in the control of hypertension (TASMINH2): a randomised controlled trial. Lancet 2010; 376(9736): 163-172

DOI: 10.3399/bjgp13X669103

\section{Authors' response}

We agree with $A^{\prime}$ Court and colleagues that the consequence of diagnosing greater numbers of people with other chronic conditions in addition to hypertension may be associated with increasing difficulties in providing access. 'The argument is that as more patients with chronic disease require regular management, the demand for appointments with GPs and practice nurses increases. This is important since some other chronic conditions are under recorded, including for example chronic obstructive pulmonary disease, chronic kidney disease, and obesity. The implications are that tackling chronic disease in this country is going to be challenging unless the capacity of primary care is increased. We also agree, however, that changing methods of diagnosis may help to reduce the numbers of people with false positive diagnoses, as may be the case in hypertension.

The suggestion that structured equation modelling offers an alternative analytic approach is interesting. However, although structured equation modelling would be possible, the fact that the associations are at the population level would mean that inferences about causality could only be supported at the population level. Perhaps this is an approach that could be used in future studies that include additional data.

\section{Richard Baker,}

University of Leicester, Department of Health Sciences, 22-28 Princess Road West, Leicester, LE1 6PT. E-mail: rb14هle.ac.uk

M John Bankart, Mohammed S Anwar, and Nicola Walker,

University of Leicester, Department of Health Sciences, Leicester.
Medical University of South Carolina, Family Medicine, Charleston, SC, US.

\section{REFERENCE}

1. A'Court A, Atherton H, Dalton A, et al. Are there enough GPs in England to detect hypertension and maintain access? [Letter]. Br J Gen Pract 2013; 63(612): 346

\section{Perinatal obsessive- compulsive disorder}

I found this article by Challacombe and Roe interesting and timely. The idea of harming your baby can be terrifying for a new mother and the distress is aggravated by the fact that such thoughts 'should not be felt' by a caring mother. Clearly the difference between obsessive-compulsive disorder (OCD) and other more serious forms of mental illness is that with OCD there is no desire to carry out the thoughts.

I have been in practice for over 30 years in Derby and feel OCD in general is underdiagnosed. When I see a patient with anxiety, problem drinking, or depression, ask if they have problems with excessive checking or contamination fears. Although I have not kept any figures, a significant number have OCD; some for years and there is often well-meant collusion with friends or relatives. Questions about OCD could be incorporated into anxiety/depression health questionnaires

OCD is often a chronic illness. Even after appropriate referral and therapy, find relapse is common. I now negotiate treatment goals with the aim of 'minimising its effects on everyday living'. Patients seem relieved about this, as they get frustrated and disappointed that their problem was not 'cured' by therapy. They are often thorough and conscientious and can make excellent parents and valued workers.

\section{Geoffrey Allen,}

E-mail: allen_chapellabtinternet.com

\section{REFERENCE}

1. Challacombe FL, Wroe AL. A hidden problem: consequences of the misdiagnosis of perinatal obsessive-compulsive disorder. Br J Gen Pract 2013; 63(610): 275-276.

DOI: 10.3399/bjgp13X669095

\section{Registrar feedback on 'Formative assessments in medical education'}

I write in support of the article 'Formative assessments in medical education' by Dr Lakasing.

I love my job as a GP registrar and look forward to qualification in a few months. Despite the contract wranglings, bad press, and the ever-increasing workload, I feel optimistic and enthused about the future.

I support most aspects of the ePortfolio process from the AKT and CSA exams to the Case-based Discussion and Consultation Observation Tool assessments. I think the patient satisfaction questionnaires and multisource feedback assessments are crucial aspects of good training, as these collate the views of the many people we are working respectively for and with.

I completely agree with Dr Lakasing about the negative impact of the requirement for writing huge volumes of reflective entries. I believe that potentially excellent GPs with the ability and energy to be involved in innovation and improvement within primary care are shackled by the need to endlessly document reflections in accordance with the curriculum. I also think that the quantity of trainee reflection must be hugely wearing for GP trainers and must put off good people from doing the job. Given the pending rise in need for GP trainers, as a profession we will need all the good people we can get.

Another problem with the 'log entries' is the variability of volume required across deaneries. In the London deanery, registrars do two entries per month. In Oxford, Kent, Surrey, and Sussex deaneries the recommended minimum is two per week. This creates inequity of training and I would suggest that the London deanery has nearer the right balance.

The recent Francis report identified the adverse consequences of box ticking on clinical care. I would suggest that excessive box ticking has the same negative impact on training. Coerced excessive written introspection erodes professionalism and motivation. It has the potential to encourage gaming and creative writing among trainees trying to keep up in a numbers game with their peers.

Compared to my friends in other specialities such as medicine, paediatrics, and psychiatry, I feel we GP registrars have a superior training programme and I am 
grateful for this. The majority of the ePortfolio is good at documenting a basic level of competence. With a sensible reduction in "log entry' volume and a rethink on the content and purpose of the clinical supervisor's report, the ePortfolio could be a fantastic aid to training. That said, what I really value in training is dedicated tutorial time with experienced GPs to talk through challenging cases and difficult scenarios. This apprenticeship-style learning and the passing on of the 'art' of medicine is invaluable and completely irreplaceable by the ePortfolio.

\section{Pete Osborne,}

GP Registrar, Burdwood Surgery, Wheelers Green Way, Thatcham, Berkshire, RG19 4YF. E-mail: peterosbornelanhs.net

Bahia Bal,

Burdwood Surgery, Wheelers Green Way, Thatcham, Berkshire.

\section{REFERENCE}

1. Lakasing E. Formative assessments in medical education: are excessive, and erode the learning and teaching experience. Br J Gen Pract 2013; 63(608): 145.

DOI: 10.3399/bjgp13X669121

\section{Paediatric consultant GP-hotline audit}

It has long been recognised that the telephone is a good way to improve communications between specialists and primary care physicians. ${ }^{1}$ Written communication is often of variable quality and poor educational value. Despite several examples of successful GP hotlines in the literature, it is an area that has never seemed to take off in the NHS. ${ }^{2}$

The paediatric consultants at St Mary's Hospital run a free advice hotline. They receive calls from local GPs between $12-2 \mathrm{pm}$ and give advice relating to queries about children. It is hoped that in addition to providing invaluable telephone support, the hotline helps to streamline or avoid paediatric referrals.

Calls to the hotline were audited over a 1-month period. The purpose of the audit was to analyse the number of GP practices using the hotline, the type of queries the calls were about, the type of advice usually given, whether the hotline avoided subsequent clinic referrals, and whether GPs were satisfied with the service.

We analysed 23 calls from 13 different

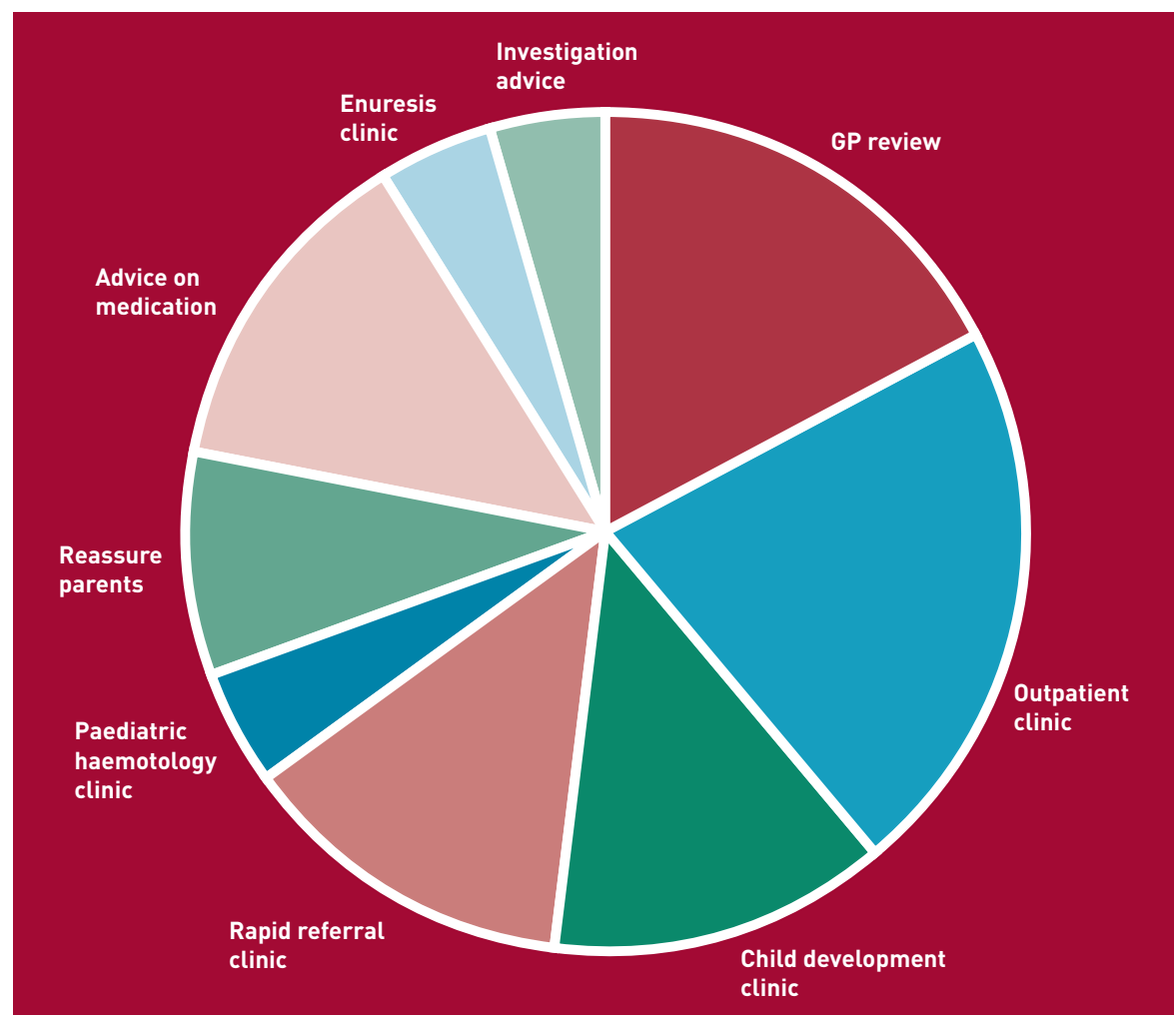

Figure 1. Patient outcomes following hotline calls.

surgeries, which account for around 25\% of the 50 practices that are located within $2 \mathrm{~km}$ of the hospital. Frequent clinical topics discussed included dermatology, gastroenterology, urology, prescribing, and behavioural problems. Some calls avoided referrals and although half of the queries resulted in a referral to paediatric outpatients, these were better directed because of the call. Approximately onethird of the queries were dealt with by reassurance and GP follow-up. (Figure 1.)

Feedback from GPs was universally positive. They liked the time slot, didn't have too much difficulty getting through, and preferred telephone contact over e-mail. Paediatricians thought providing the service was worthwhile and appreciated the opportunity for case discussion and strengthening links with local GPs.

We think that the GP hotline is a successful, useful, and much appreciated service that succeeds in preventing inappropriate referrals and directing necessary referrals to the correct clinic. The service is underused at present and there is a need to publicise it more. A voicemail option would be useful, particularly if usage increases: topics for future GP education would be paediatric prescribing and dermatology.

A new referral template for paediatric outpatients is in development which will have the paediatric hotline number prominently displayed to encourage GPs to consider calling for advice before making a formal referral.

Mando Watson,

The Bays, South Wharf Road, St Mary's Hospital, London, W2 1NY.

E-mail: mando.watsondimperial.nhs.uk

Robert Klaber,

Imperial College Healthcare NHS Trust, St Mary's Hospital, London.

Chiara Haynes,

37 Woodbury Drive, Sutton, Surrey.

Katherine Holt,

Flat 4, 190 Brixton Road, London.

Morag Lenman,

34 Bramfield Road, London.

\section{REFERENCES}

1. Harrison R, Clayton W, Wallace P. Can telemedicine be used to improve communication between primary and secondary care? BMJ 1996; 313(7069): 1377-1380.

2. Roland M, Bewley B. Boneline: evaluation of an initiative to improve communication between specialists and general practitioners. J Public Health Med 1992; 14(3): 307-309.

DOI: 10.3399/bjgp13X669130 